\title{
TRF2 and the evolution of the bilateria
}

\author{
Sascha H.C. Duttke, ${ }^{1}$ Russell F. Doolittle, ${ }^{1,2}$ Yuan-Liang Wang, ${ }^{1}$ and James T. Kadonaga ${ }^{1}$ \\ ${ }^{1}$ Section of Molecular Biology, University of California at San Diego, La Jolla, California 92093, USA; ${ }^{2}$ Department of Chemistry \\ and Biochemistry, University of California at San Diego, La Jolla, California 92093, USA
}

The development of a complex body plan requires a diversity of regulatory networks. Here we consider the concept of TATA-box-binding protein (TBP) family proteins as "system factors" that each supports a distinct set of transcriptional programs. For instance, TBP activates TATA-box-dependent core promoters, whereas TBP-related factor 2 (TRF2) activates TATA-less core promoters that are dependent on a TCT or downstream core promoter element (DPE) motif. These findings led us to investigate the evolution of TRF2. TBP occurs in Archaea and eukaryotes, but TRF2 evolved prior to the emergence of the bilateria and subsequent to the evolutionary split between bilaterians and nonbilaterian animals. Unlike TBP, TRF2 does not bind to the TATA box and could thus function as a new system factor that is largely independent of TBP. We postulate that this TRF2-based system served as the foundation for new transcriptional programs, such as those involved in triploblasty and body plan development, that facilitated the evolution of bilateria.

Supplemental material is available for this article.

The development of complex body plans requires a diverse range of transcriptional programs. The regulation of these programs is often analyzed at the level of sequencespecific DNA-binding proteins that interact with enhancers and other important DNA elements. Indeed, sequencespecific factors, such as those that are used to create induced pluripotent stem cells, play a critical and dominant role in establishing the state of a cell. However, at the same time, it might be imagined that the most farreaching changes in an organism would involve alterations of the basal transcriptional machinery.

In eukaryotes, the basic transcription reaction involves an RNA polymerase along with auxiliary factors that are required for accurate and efficient transcription. For transcription of the subset of promoters that contain a TATA box, RNA polymerase II (Pol II) functions with transcription factor IIB (TFIIB), TFIID, TFIIE, TFIIF, and TFIIH (for review, see Thomas and Chiang 2006). TFIID comprises the TATA-box-binding protein (TBP) along with other TBP-associated factors known as TAFs. In

[Keywords: RNA polymerase II; TRF2; TBP; evolution; bilateria; regulatory systems]

Corresponding author: jkadonaga@ucsd.edu

Article is online at http://www.genesdev.org/cgi/doi/10.1101/gad.250563.114. addition, TFIIA has been found to enhance the binding of TBP to DNA. TBP (as well as the TATA box), TFIIB, TFIIE, TFIIS, and Pol II are present in Archaea and eukaryotes (for review, see Grohmann and Werner 2011). Moreover, many eukaryotes contain TBP as well as TBP-related factors (TRFs).

Here we consider the concept that TBP family proteins function as "system factors" that support distinct transcriptional programs. TBP occurs in Archaea and eukaryotes, and TBP-related factor 1 (TRF1), TRF2, and TRF3 (for reviews, see Goodrich and Tjian 2010; Akhtar and Veenstra 2011) evolved independently via duplications of the TBP gene. TRF1 has been found in insects, TRF3 appears to be present mainly in vertebrates, and TRF2 has been generally thought to be present in all metazoans (Dantonel et al. 1999; Goodrich and Tjian 2010; Akhtar and Veenstra 2011). Except for TRF2, members of the TBP family of proteins exhibit sequence-specific binding to DNA.

Here we focus on two RNA Pol II transcriptional programs that are driven by the TBP or TRF2 system factors. We then analyze the characteristics and emergence of TRF2 and propose a role for the TRF2-based system in the evolution of the bilateria, triploblastic animals that have bilateral symmetry and represent $\sim 99 \%$ of all living animals.

System factors function via the core promoter, which is the segment of DNA that is sufficient to direct accurate initiation of transcription (for example, see Kadonaga 2012 and references therein). The signals that regulate transcription must ultimately pass through the core promoter, and it thus serves as the "gateway to transcription." The RNA Pol II core promoter is diverse in terms of its structure and function, and its activity is regulated by the presence or absence of specific DNA sequence motifs. These core promoter elements include the TATA box, initiator (Inr), polypyrimidine initiator (TCT), and downstream core promoter element (DPE). There are no universal core promoter motifs. TBP family system factors can act through specific core promoter motifs, although in a manner that may or may not involve direct binding to those DNA sequence elements.

(C) 2014 Duttke et al. This article is distributed exclusively by Cold Spring Harbor Laboratory Press for the first six months after the full-issue publication date (see http://genesdev.cshlp.org/site/misc/terms.xhtml). After six months, it is available under a Creative Commons License (Attribution-NonCommercial 4.0 International), as described at http:// creativecommons.org/licenses/by-nc/4.0/. 


\section{Distinct transcriptional programs with TBP vs. TRF2 system factors}

TBP can activate transcription via the TATA-box motif, and both TBP and the TATA box are conserved in Archaea and eukaryotes (Kosa et al. 1997; Patikoglou et al. 1999). TBP binds to the TATA box with its core region, which consists of two structurally repeated domains that form a saddle-shaped structure. For the purposes of this discussion, it is important to remember that the binding of TBP to the TATA box includes the participation of two pairs of conserved Phe residues (F193-F210 and F284-F301 in human TBP) whose side chains intercalate between the first and last base pairs of the TATA motif and kink the DNA (Fig. 1A; Supplemental Fig. S1; Kim et al. 1993a,b). This interaction is highly conserved (Patikoglou et al. 1999). In addition, TBP binds to other basal transcription factors such as TFIIA and TFIIB as well as TAFs (for review, see Thomas and Chiang 2006).
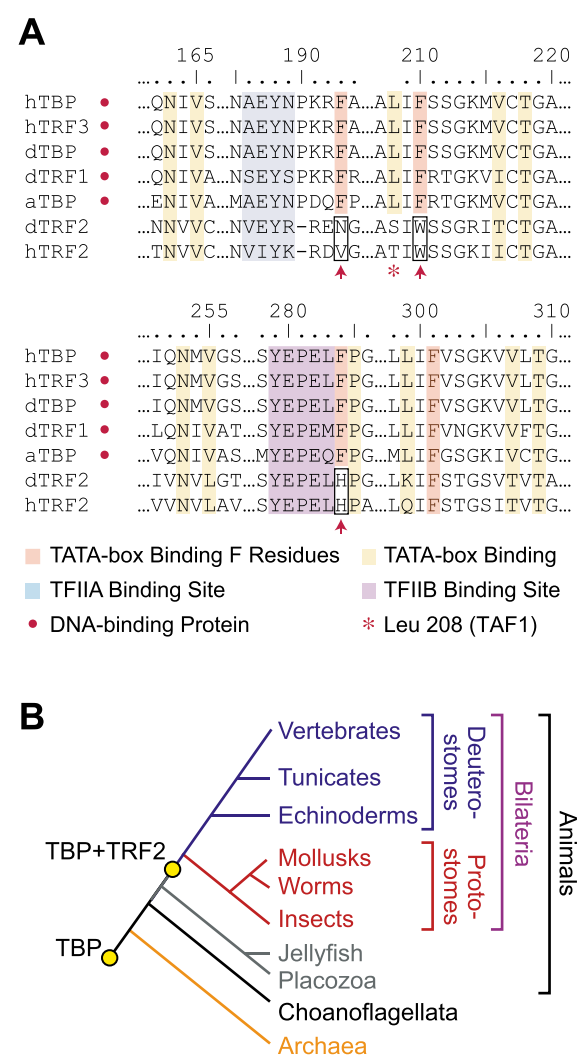

Figure 1. Evolution of the TRF2-based transcription system facilitated the emergence of complex animal body plans. (A) Alignment of TBP and TBP-related factors from Archaea (a), Drosophila (d), and humans (h). The TATA-box-interacting Phe residues that are mutated in TRF2 are indicated with arrows. The amino acid numbers are those of human TBP. The full amino acid sequences of the repeated core domains of these proteins are given in Supplemental Figure S1. (B) TRF2 emerged from a previously duplicated TBP protein prior to the evolution of bilateria and subsequent to the evolutionary split between bilaterians and nonbilaterian animals. A phylogenetic tree showing the presence or absence of TRF2 in selected metazoa is shown in Supplemental Figure S3.
TRF2 (also known as TLP, TRP, TLF, and TBPL1) (Maldonado 1999; Moore et al. 1999; Ohbayashi et al. 1999; Rabenstein et al. 1999; Teichmann et al. 1999) contains two domains that are similar to those in TBP and interacts with TFIIA and TFIIB, as does TBP (Fig. 1A; Supplemental Fig. S1). In addition, the overall structures of TBP and TRF2 are predicted to be conserved (Dantonel et al. 1999). Unlike TBP, however, TRF2 does not bind to the TATA box and does not exhibit sequence-specific binding to DNA in the presence or absence of all possible combinations of TFIIA and TFIIB (for example, see Wang et al. 2014).

TRF2, but not TBP, is required for transcription of core promoters, such as those of most ribosomal protein genes, that lack a TATA box and are dependent on the TCT sequence motif (Wang et al. 2014). On the other hand, TBP, but not TRF2, is essential for the transcription of TATA-dependent core promoters. These findings revealed that TRF2, but not TBP, supports a TCT-dependent RNA Pol II transcription program that is dedicated to the production of ribosomal proteins. Notably, the TRF2-TCT transcriptional program complements the RNA Pol I and RNA Pol III transcriptional programs that are dedicated to the synthesis of rRNAs and tRNAs (Supplemental Fig. S2).

In addition, transcription from DPE-dependent core promoters requires TRF2 (Kedmi et al. 2014) but not TBP (Hsu et al. 2008). These TATA-less DPE-containing promoters include those of most of the homeotic genes (Juven-Gershon et al. 2008) as well as of many genes that are regulated by the Dorsal transcription factor (Zehavi et al. 2014). It is important to note that the DPE motif functions with the Inr element but not with the TCT motif (Parry et al. 2010; Kadonaga 2012). Thus, the TCTdependent promoters are different from the DPEdependent promoters. Hence, for RNA Pol II, these studies have revealed three distinct transcriptional programs: the TBP-based transcription of TATA-dependent core promoters and the TRF2-based transcription of TCT-dependent core promoters and DPE-dependent core promoters.

\section{TRF2 evolved prior to the emergence of the bilateria}

The identification of distinct TBP- and TRF2-based transcriptional programs led us to investigate the evolution of TRF2. We found paralogs of TBP in several protist lineages and in plants and animals but not in yeast. It was necessary, however, to employ a distinct and reliable signature for TRF2. To this end, we generated an alignment of TBP and TBP-related factors (Fig. 1A; Supplemental Fig. S1). Many features, such as the TFIIA and TFIIB interaction sites as well as most of the TATA-boxinteracting amino acid residues, are conserved among TBP and TBP-related factors. As described previously (Dantonel et al. 1999), three of the four conserved TATA-interacting Phe residues in TBP are altered in TRF2. The alteration of the Phe residues in TRF2 may explain the apparent absence of its binding to DNA. In addition, Leu208, which is essential for TAF1-mediated 
inhibition of TBP (Nishikawa et al. 1997), is absent in TRF2 (Fig. 1A; Supplemental Fig. S1).

We therefore examined the occurrence of TRF2 during the course of evolution by following the alteration of the three TATA-interacting Phe residues. TRF2 was found in all bilaterian genomes $(n=165)$ but not in any of the six nonbilaterian animal genomes that are currently available (one placozoan, two cnidaria, two ctenophores, and one poriferan) (Supplemental Table 1). The bilateria have bilateral symmetry and are triploblastic (i.e., possess three germ layers: endoderm, mesoderm, and ectoderm). This is in contrast, for instance, to the cnidaria, which have radial symmetry and are diploblastic with two germ layers (endoderm and ectoderm) (for review, see Technau and Steele 2011).

Hence, the TRF2 gene was already present in the last common ancestor of all bilaterians, having evolved from a duplicated TBP gene (Fig. 1B; Supplemental Figs. S3, S4A). It is interesting to note that the changes from Phe to Trp as well as from Phe to His each required a minimum of two nucleotide substitutions in the DNA sequence. Thus, the alteration of the three Phe residues involved a minimum of five nucleotide substitutions, which may have been due to positive selection. We identified two copies of TBP genes (which, incidentally, encode proteins with all four of the TATA-interacting Phe residues) in one placozoan, one ctenophore (Pleurobrachia bachei), and two choanoflagellates, the presumed closest living relatives of animals. None of these genes, however, appears to be the predecessor of the TRF2 gene (data not shown).

The inability of TRF2 to bind to the TATA box may have led to a partial loss of evolutionary constraints in TRF2 relative to TBP. Consistent with this idea, the amino acid substitution rate in TRF2 was approximately five times higher than that in TBP (Supplemental Fig. S4). For some reason, the amino acid substitution rate in TRF2 slowed down significantly during vertebrate evolution.

It is also relevant to mention that the independent replacement of some of the TATA-interacting Phe residues in TBP, but not the characteristic three Phe residues altered in TRF2, has occurred in some protists. For instance, the trypanosome Trypanosoma brucei has lost the first two Phe residues, and the dinoflagellate Crypthecodinium cohnii has lost all four Phe residues (Guillebault et al. 2002; Ruan et al. 2004). Both species appear to encode only one copy of a TBP family protein. Consistent with the modification of their critical Phe residues, TATA-box-containing promoters were not found in either species (Guillebault et al. 2002; Ruan et al. 2004; Das et al. 2005). These findings provide examples in which the TATA-interacting Phe residues had been altered independently of TRF2.

\section{TRF2 and the evolution of bilateria}

The split of the TBP-based transcription system into the TBP- and TRF2-driven systems predates the evolution of complex body plans. Because TRF2 does not bind to the TATA box, it can function somewhat independently of the pre-existing TATA-dependent TBP-based transcription systems. It is likely that the new TRF2-based transcrip- tion system facilitated the emergence of new transcriptional programs, such as those of core promoters that are driven by a DPE or TCT motif (Kedmi et al. 2014; Wang et al. 2014). In addition, the Drosophila histone H1 promoter, which does not appear to contain a TCT or DPE core promoter motif, requires TRF2 but not TBP (Isogai et al. 2007; Wang et al. 2014). Hence, there may be at least a third TRF2-based transcriptional program in addition to the TCT and DPE networks.

To investigate the biological functions of TRF2, ontology analysis was performed with genes $(n=1475)$ associated with promoters that were found to contain at least a twofold higher level of TRF2 occupancy relative to background in 2- to 4-h Drosophila embryos. This analysis revealed a strong relation between TRF2 and translation as well as development and cell differentiation (Supplemental Table 2). These findings are consistent with the role of the TCT motif in the transcription of genes involved in translation (ribosomal protein genes and translation initiation and elongation factor genes) (Parry et al. 2010) as well as with the function of the DPE in the transcription of genes involved in development and cell differentiation (homeotic genes and Dorsal target genes) (Juven-Gershon et al. 2008; Zehavi et al. 2014). It is particularly notable that some of the Dorsal-regulated genes, such as twist, Mef2, and tinman, are important for the development of mesoderm (for example, see Bonn and Furlong 2008), which is lacking in diploblastic nonbilaterian animals such as cnidaria (Technau and Steele 2011).

Thus, in light of the timing of the appearance of TRF2 and the emergence of the bilateria as well as the role of TRF2 in development, we hypothesize that TRF2 facilitated the evolution of the bilateria through the formation of new transcriptional programs. We envision a scenario in which the TBP gene was duplicated. Then, the codons corresponding to the three critical Phe residues in one of the two TBP genes mutated over time. This yielded a protein, TRF2, that did not bind to the TATA motif yet retained other key properties of TBP, such as interactions with TFIIA and TFIIB. These functions enabled TRF2 to function as a transcription factor that did not require the TATA box. (It is useful to remember that the alteration of the Phe residues [although not the same three Phe residues as in TRF2] in the single TBP gene in protists had also resulted in factors that did not function via the TATA box [Guillebault et al. 2002; Ruan et al. 2004; Das et al. 2005].) The emergence of TRF2 thus resulted in two (largely but not entirely) independent system factors: TBP and TRF2. Importantly, TRF2 was not constrained to function via the TATA box. This situation led to the formation of new transcriptional programs, such as the TRF2-based TCT and DPE networks (Fig. 2; Kedmi et al. 2014; Wang et al. 2014). We postulate that TRF2-based transcriptional programs that are involved in triploblasty and body plan development ultimately led to the appearance of bilateria.

Consistent with the notion that TRF2 facilitated the emergence of bilateria, mutant Drosophila embryos with reduced levels of TRF2 exhibit homeotic and segmenta- 
Duttke et al.

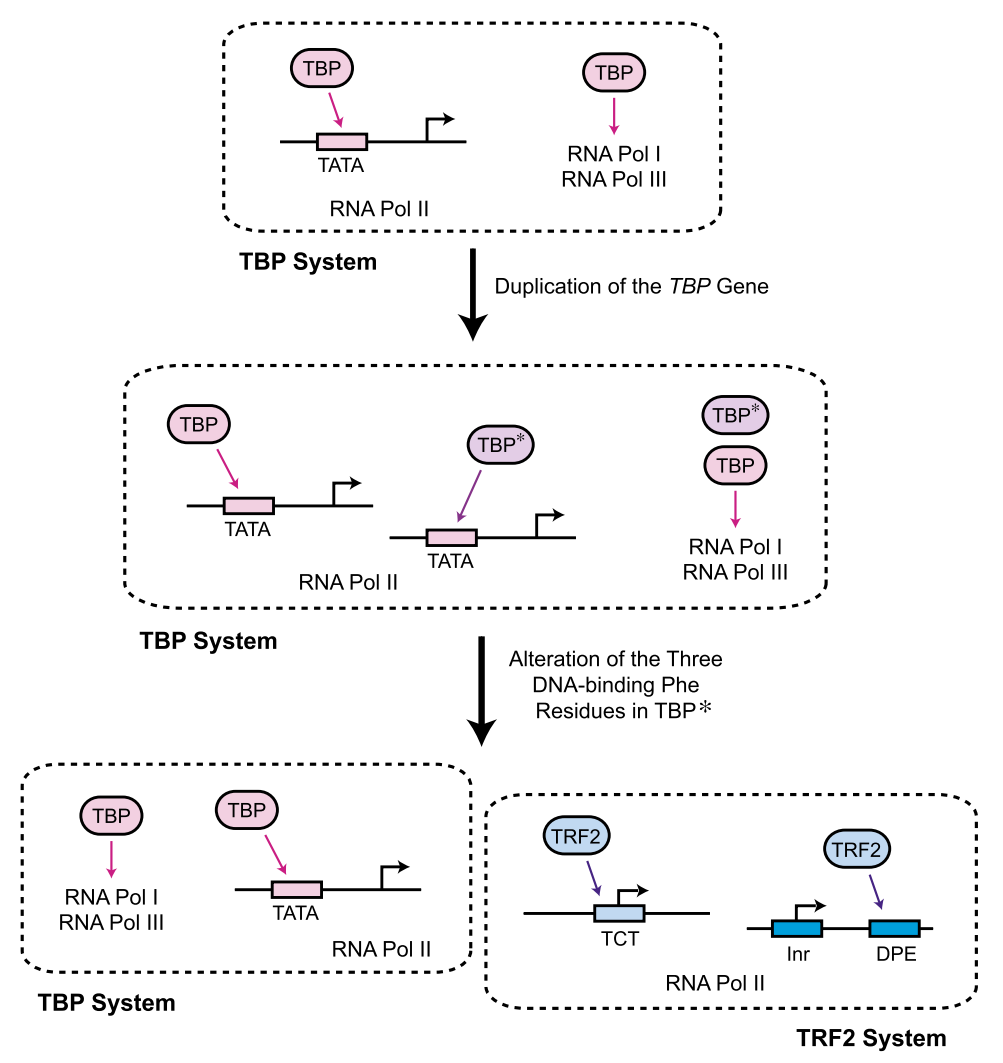

Figure 2. Postulated model for the evolution of the TRF2-based transcription system. We use $\mathrm{TBP}^{\star}$ as a general notation for a TBP-related protein that contains all four of the TATA-box-interacting Phe residues. The TBP system comprises the RNA Pol II TATA box program, the RNA Pol I and RNA Pol III transcriptional programs, and probably other programs. The TRF2 system includes the TCT and DPE transcriptional programs and probably other programs, such as one that transcribes histone $\mathrm{Hl}$ genes. The DPE functions with the Inr but not with the TCT motif (Parry et al. 2010; Kadonaga 2012). Therefore, the TCT and DPE transcriptional programs are distinct. TBP binds directly to the TATA-box motif, whereas purified TRF2 does not appear to bind to the TATA box or any other specific DNA sequence. Because of this difference in the DNA-binding properties of TBP and TRF2, these two system factors can function somewhat independently of each other. This facilitated the evolution of two distinct transcriptional systems.

tion defects as well as abnormalities in the dorsal-ventral polarity (Kopytova et al. 2006). In worms, fish, and frogs, the decrease or inactivation of TRF2 has been found to be embryonically lethal, with development arrested prior to gastrulation (Dantonel et al. 2000; Kaltenbach et al. 2000; Veenstra et al. 2000; Müller et al. 2001). In contrast, however, TRF2-deficient mice were observed to be viable, although they exhibited a defect in spermiogenesis (Martianov et al. 2001; Zhang et al. 2001). In mice, it is possible that there is some other factor that compensates for the absence of TRF2.

This hypothesis for the evolution of bilaterians could be tested by gaining a better understanding of TRF2-based transcriptional programs as well as the molecular processes that differ between bilaterians and nonbilaterian animals. In this manner, it could be seen whether TRF2-regulated gene networks are intimately linked to the specific functions that were essential for the development of bilaterians.

\section{System factors and 'operating systems' (OSs)}

In conclusion, we view TBP family proteins as "system factors" that drive multiple transcriptional programs (Fig. 3 ). In some respects, this arrangement has a resemblance to computer OSs and programs (applications or "apps"). By following this analogy, we might imagine that TBP and TRF2 each represent an OS and that specific transcriptional programs, such as Pol I, Pol II-TATA, Pol III, Pol IIDPE, and Pol II-TCT, are "apps" that function with their cognate OS. From this perspective, the establishment of TRF2 provided a new "TRF2 OS" that could function in addition to the pre-existing "TBP OS," and this arrangement led to new "apps" that facilitated the emergence of bilateria. In the future, the analysis of system factors and their unique and important roles in transcription should continue to yield many new and fascinating biological insights.

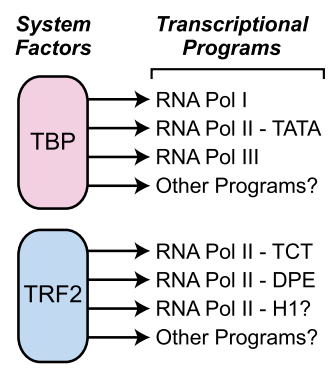

Figure 3. Model of TBP and TRF2 as system factors with their associated transcriptional programs. We postulate that the emergence of TRF2, which does not bind to the TATA box, provided a new and somewhat independent TRF2-based transcription system that could function in addition to the preexisting TBP-based system. We propose that this arrangement led to new transcriptional programs that facilitated triploblasty and the evolution of bilateria. 


\section{Acknowledgments}

Dedicated to Robert Tjian on the occasion of his 65th birthday and in recognition of his contributions to our understanding of TBP-related factors. We thank Robert Tjian, Bill McGinnis, Mike Levine, Minsung Kim, George Kassavetis, Jia Fei, and Rebecca Wright for critical reading of the manuscript. We additionally express our gratitude to Tammy Juven-Gershon for sharing data prior to publication. We also thank Jeff Johnston and Casey Romanoski for help with the analysis of TRF2 chromatin immunoprecipitation sequencing (ChIP-seq) data. J.T.K. is the Amylin Chair in the Life Sciences. S.H.C.D. is the recipient of the University of California at San Diego Molecular Biology/Cancer Center Fellowship. This work was supported by National Institutes of Health grant R01 GM041249 to J.T.K.

\section{References}

Akhtar W, Veenstra GJ. 2011. TBP-related factors: a paradigm of diversity in transcription initiation. Cell Biosci 1: 23.

Bonn S, Furlong EEM. 2008. Cis-regulatory networks during development: a view of Drosophila. Curr Opin Genet Dev 18: $513-520$.

Dantonel JC, Wurtz JM, Poch O, Moras D, Tora L. 1999. The TBP-like factor: an alternative transcription factor in metazoa? Trends Biochem Sci 24: 335-339.

Dantonel JC, Quintin S, Lakatos L, Labouesse M, Tora L. 2000. TBP-like factor is required for embryonic RNA polymerase II transcription in C. elegans. Mol Cell 6: 715-722.

Das A, Zhang Q, Palenchar JB, Chatterjee B, Cross GAM, Bellofatto V. 2005. Trypanosomal TBP functions with the multisubunit transcription factor tSNAP to direct splicedleader RNA gene expression. Mol Cell Biol 25: 7314-7322.

Goodrich JA, Tjian R. 2010. Unexpected roles for core promoter recognition factors in cell-type-specific transcription and gene regulation. Nat Rev Genet 11: 549-558.

Grohmann D, Werner F. 2011. Recent advances in the understanding of archaeal transcription. Curr Opin Microbiol 14: $328-334$.

Guillebault D, Sasorith S, Derelle E, Wurtz JM, Lozano JC, Bingham S, Tora L, Moreau H. 2002. A new class of transcription initiation factors, intermediate between TATA box-binding proteins (TBPs) and TBP-like factors (TLFs), is present in the marine unicellular organism, the dinoflagellate Crypthecodinium cohnii. I Biol Chem 277: 4088140886.

Hsu JY, Juven-Gershon T, Marr MT 2nd, Wright KJ, Tjian R, Kadonaga JT. 2008. TBP, Mot1, and NC2 establish a regulatory circuit that controls DPE-dependent versus TATAdependent transcription. Genes Dev 22: 2353-2358.

Isogai Y, Keles S, Prestel M, Hochheimer A, Tjian R. 2007. Transcription of histone gene cluster by differential corepromoter factors. Genes Dev 21: 2936-2949.

Juven-Gershon T, Hsu JY, Kadonaga JT. 2008. Caudal, a key developmental regulator, is a DPE-specific transcription factor. Genes Dev 22: 2823-2830.

Kadonaga JT. 2012. Perspectives on the RNA polymerase II core promoter. WIREs Dev Biol 1: 40-51.

Kaltenbach L, Horner MA, Rothman JH, Mango SE. 2000. The TBP-like factor CeTLF is required to activate RNA polymerase II transcription during C. elegans embryogenesis. Mol Cell 6: 705-713.

Kedmi A, Zehavi Y, Glick Y, Orenstein Y, Ideses D, Wachtel C, Doniger T, Waldman Ben-Asher H, Muster N, Thompson J, et al. 2014. Drosophila TRF2 is a preferential core promoter regulator. Genes Dev 28: (this issue). doi: 10.1101/gad.245670.114.
Kim Y, Geiger JH, Hahn S, Sigler PB. 1993a. Crystal structure of a yeast TBP/TATA-box complex. Nature 365: 512-520.

Kim JL, Nikolov DB, Burley SK. 1993b. Co-crystal structure of TBP recognizing the minor groove of a TATA element. Nature 365: 520-527.

Kopytova DV, Krasnov AN, Kopantceva MR, Nabirochkina EN, Nikolenko JV, Maksimenko O, Kurshakova MM, Lebedeva LA, Yerokhin MM, Simonova OB, et al. 2006. Two isoforms of Drosophila TRF2 are involved in embryonic development, premeiotic chromatin condensation, and proper differentiation of germ cells of both sexes. Mol Cell Biol 26: 7492-7505.

Kosa PF, Ghosh G, DeDecker BS, Sigler PB. 1997. The 2.1crystal structure of an archaeal preinitiation complex: TATAbox-binding protein/transcription factor (II)B core/TATA-box. Proc Natl Acad Sci 94: 6042-6047.

Maldonado E. 1999. Transcriptional functions of a new mammalian TATA-binding protein-related factor. I Biol Chem 274: 12963-12966.

Martianov I, Fimia GM, Dierich A, Parvinen M, Sassone-Corsi P, Davidson I. 2001. Late arrest of spermiogenesis and germ cell apoptosis in mice lacking the TBP-like TLF/TRF2 gene. Mol Cell 7: 509-515.

Moore PA, Ozer J, Salunek M, Jan G, Zerby D, Campbell S, Lieberman PM. 1999. A human TATA binding proteinrelated protein with altered DNA binding specificity inhibits transcription from multiple promoters and activators. Mol Cell Biol 19: 7610-7620.

Müller F, Lakatos L, Dantonel J, Strähle U, Tora L. 2001. TBP is not universally required for zygotic RNA polymerase II transcription in zebrafish. Curr Biol 11: 282-287.

Nishikawa JI, Kokubo T, Horikoshi M, Roeder RG, Nakatani Y. 1997. Drosophila TAFII230 and the transcriptional activator VP16 bind competitively to the TATA box-binding domain of the TATA box-binding protein. Proc Natl Acad Sci 94: 85-90.

Ohbayashi T, Makino Y, Tamura TA. 1999. Identification of a mouse TBP-like protein (TLP) distantly related to the Drosophila TBP-related factor. Nucleic Acids Res 27: 750-755.

Parry TJ, Theisen JW, Hsu JY, Wang YL, Corcoran DL, Eustice M, Ohler U, Kadonaga JT. 2010. The TCT motif, a key component of an RNA polymerase II transcription system for the translational machinery. Genes Dev 24: 20132018.

Patikoglou GA, Kim JL, Sun LP, Yang SH, Kodadek T, Burley SK. 1999. TATA element recognition by the TATA box-binding protein has been conserved throughout evolution. Genes Dev 13: 3217-3230.

Rabenstein MD, Zhou S, Lis JT, Tjian R. 1999. TATA boxbinding protein (TBP)-related factor 2 (TRF2), a third member of the TBP family. Proc Natl Acad Sci 96: 4791-4796.

Ruan JP, Arhin GK, Ullu E, Tschudi C. 2004. Functional characterization of a Trypanosoma brucei TATA-binding protein-related factor points to a universal regulator of transcription in trypanosomes. Mol Cell Biol 24: 96109618.

Technau U, Steele RE. 2011. Evolutionary crossroads in developmental biology: cnidaria. Development 138: 1447-1458.

Teichmann M, Wang Z, Martinez E, Tjernberg A, Zhang D, Vollmer F, Chait BT, Roeder RG. 1999. Human TATAbinding protein-related factor-2 (hTRF2) stably associates with hTFIIA in HeLa cells. Proc Nat1 Acad Sci 96: 1372013725.

Thomas MC, Chiang CM. 2006. The general transcription machinery and general cofactors. Crit Rev Biochem Mol Biol 41: 105-178. 
Duttke et al.

Veenstra GJ, Weeks DL, Wolffe AP. 2000. Distinct roles for TBP and TBP-like factor in early embryonic gene transcription in Xenopus. Science 290: 2312-2315.

Wang YL, Duttke SHC, Chen K, Johnston J, Kassavetis GA, Zeitlinger J, Kadonaga JT. 2014. TRF2, but not TBP, mediates the transcription of ribosomal protein genes. Genes Dev 28: $1550-1555$.

Zehavi Y, Kuznetsov O, Ovadia-Shochat A, Juven-Gershon T. 2014. Core promoter functions in the regulation of Drosophila Dorsal target genes. J Biol Chem 289: 11993-12004.

Zhang D, Penttila TL, Morris PL, Teichmann M, Roeder RG. 2001. Spermiogenesis deficiency in mice lacking the Trf2 gene. Science 292: 1153-1155. 


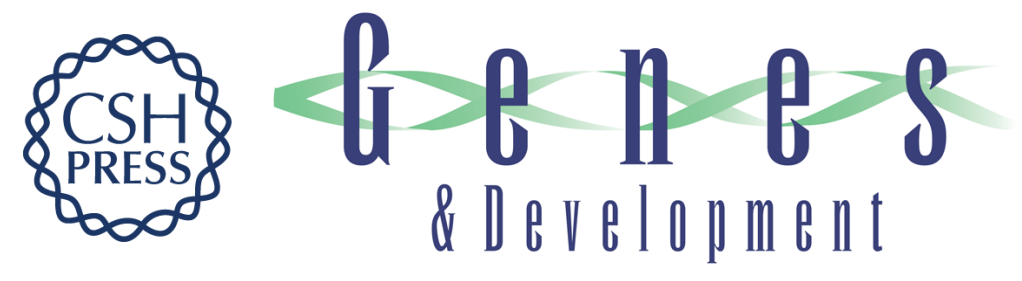

\section{TRF2 and the evolution of the bilateria}

Sascha H.C. Duttke, Russell F. Doolittle, Yuan-Liang Wang, et al.

Genes Dev. 2014, 28:

Access the most recent version at doi:10.1101/gad.250563.114

\section{Supplemental http://genesdev.cshlp.org/content/suppl/2014/09/29/28.19.2071.DC1 \\ Material}

Related Content Drosophila TRF2 is a preferential core promoter regulator

Adi Kedmi, Yonathan Zehavi, Yair Glick, et al.

Genes Dev. October , 2014 28: 2163-2174

References This article cites 35 articles, 21 of which can be accessed free at: http://genesdev.cshlp.org/content/28/19/2071.full.html\#ref-list-1

Articles cited in: http://genesdev.cshlp.org/content/28/19/2071.full.html\#related-urls

Creative This article is distributed exclusively by Cold Spring Harbor Laboratory Press for the first Commons six months after the full-issue publication date (see

License http://genesdev.cshlp.org/site/misc/terms.xhtml). After six months, it is available under a Creative Commons License (Attribution-NonCommercial 4.0 International), as described at http://creativecommons.org/licenses/by-nc/4.0/.

Email Alerting Receive free email alerts when new articles cite this article - sign up in the box at the top Service right corner of the article or click here.

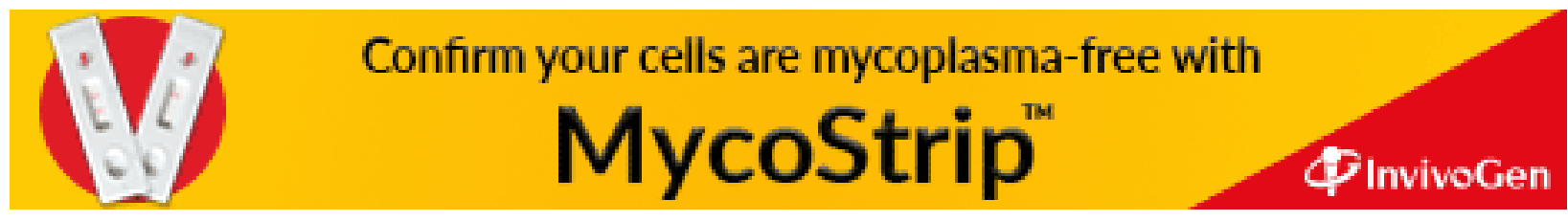

